\title{
LA-UR-20-25286
}

Approved for public release; distribution is unlimited.

Title: $\quad$ Mechanistic Approach to Analyzing and Improving Unconventional Hydrocarbon Production

Author(s): $\quad$ Viswanathan, Hari S.

Guthrie, George Drake Jr.

Carey, James William

Intended for: $\quad$ DOE Headquarters Briefing

Issued: 2020-07-17 
Disclaimer:

Los Alamos National Laboratory, an affirmative action/equal opportunity employer, is operated by Triad National Security, LLC for the National Nuclear Security Administration of U.S. Department of Energy under contract 89233218CNA000001. By approving this article, the publisher recognizes that the U.S. Government retains nonexclusive, royalty-free license to publish or reproduce the published form of this contribution, or to allow others to do so, for U.S. Government purposes. Los Alamos National Laboratory requests that the publisher identify this article as work performed under the auspices of the U.S. Department of Energy. Los Alamos National Laboratory strongly supports academic freedom and a researcher's right to publish; as an institution, however, the Laboratory does not endorse the viewpoint of a publication or guarantee its technical correctness. 


\section{Mechanistic Approach to Analyzing and Improving Unconventional Hydrocarbon Production}

Hari Viswanathan and Bill Carey

Program Manager: Bruce Brown
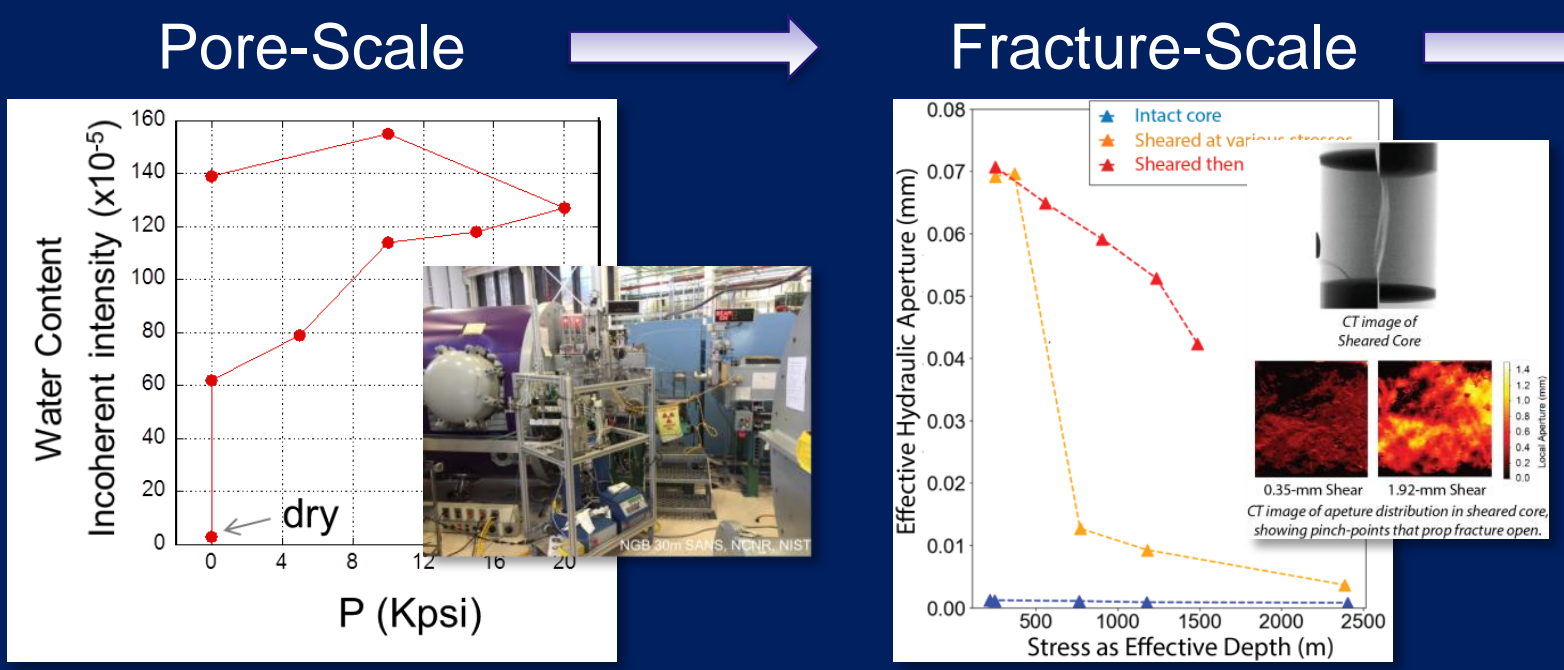

\section{Reservoir-Scale}

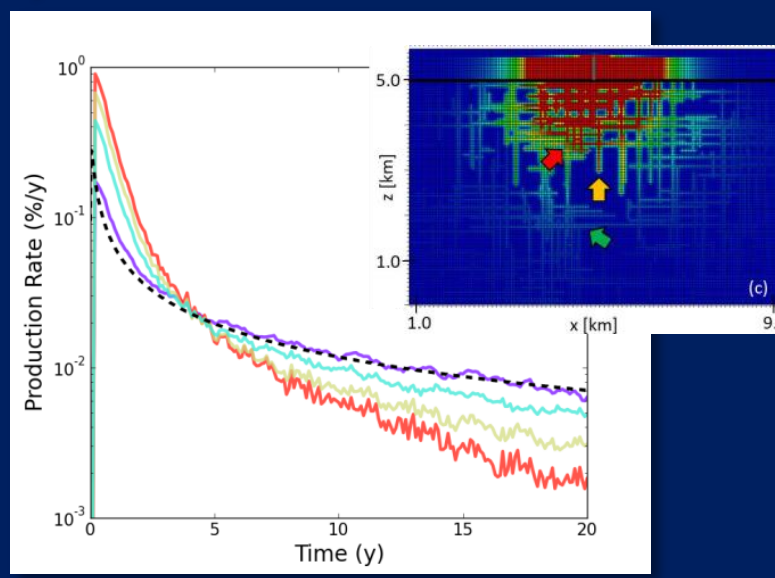

Luke Frash, George Guthrie, Qinjun Kang, Satish Karra, Natalita Makedonska, Chelsea Neil, Matt Sweeney, Nathan Welch, Hongwu Xu

2020 DOE FE Fundamental Shale Progress

July 142020 


\section{DOE research is developing the physical basis and tools needed to manage pressure effectively to increase recovery efficiency.}

- Slower drawdown rates can lead to improved recovery efficiency in gas production from shale

$>$ Anecdotal evidence from field experiences

- Yet, slower drawdown requires an operator to forego high near-term production for higher overall production.

- DOE research will help operators to assess the riskbenefit for managing pressure.

> Uncertain site-specific characteristics/behavior (risk)

$>$ Increased recovery with slower drawdown (benefit)

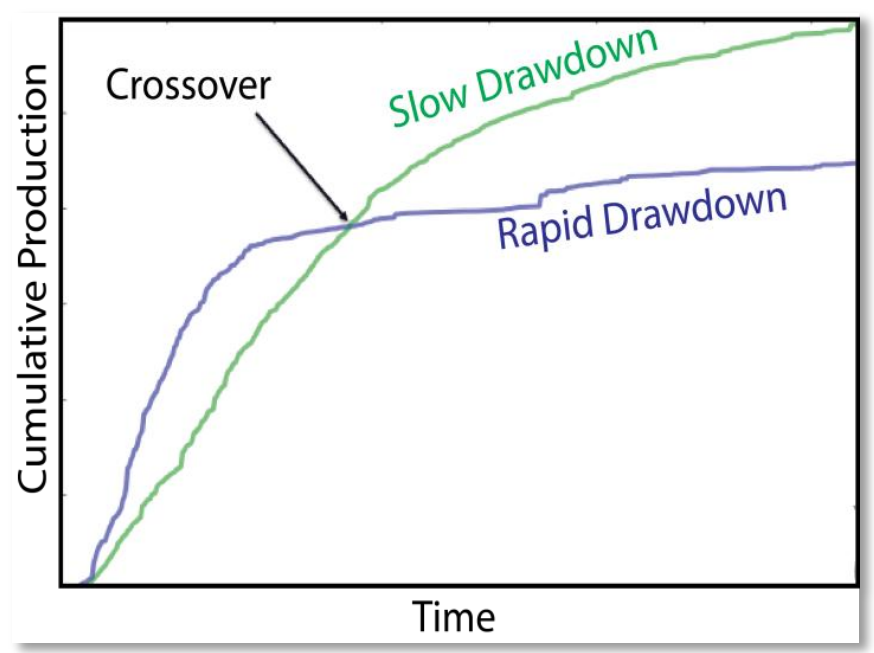

Fast, Accurate Predictions of the Behavior of Fractured Reservoirs

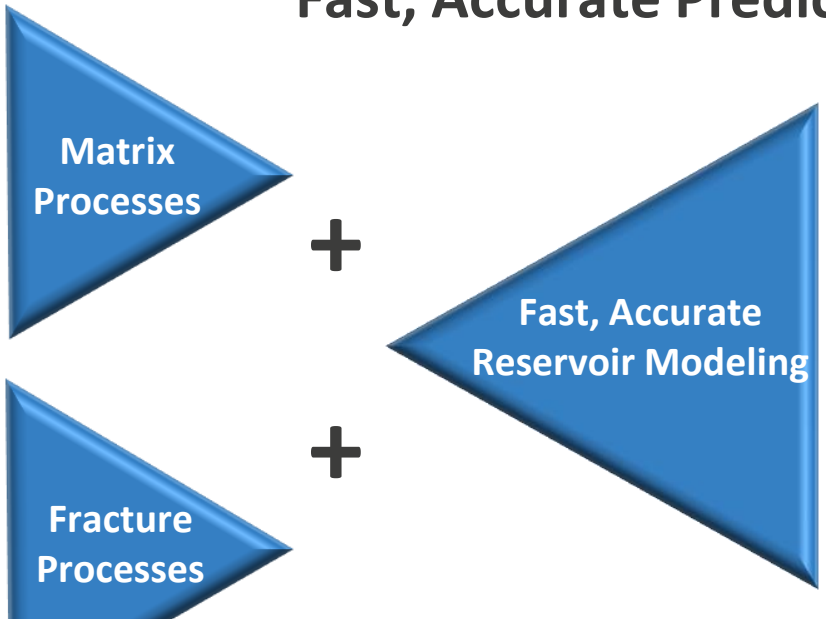

Physically Realistic Synthetic Data

(Forecasts of pressure-dependent behavior with

an accuracy sufficient to optimize operations) 


\section{By coupling fast, accurate physics with machine learning, DOE is producing science-based platforms any operator can use.}

Strategy: Physically realistic, site-specific synthetic data can be used in combination with available site data to confidently extrapolate production different operational decisions.



Physically Realistic Synthetic Data



Physical behavior of system described as a combination of fracture transport and matrix-scale transport

- Theoretical development and experimental characterization occurring through FE-30 investments

Fast, accurate reservoir-scale simulations using discrete-fracture network platform in combination with graph-based models \& machine learning

- Initial development with LDRD

- Extension to gas in shales through FE-30

Machine learning applied to scenarios library that augments limited/no field data with synthetic for real-time optimization

- Platform development through FE-30 


\section{DOE's research portfolio is targeting hydrocarbon transport at multiple scales, with the goal of increasing recovery efficiency.}

\section{Increasing both the peak and tail are important for increasing recovery.}

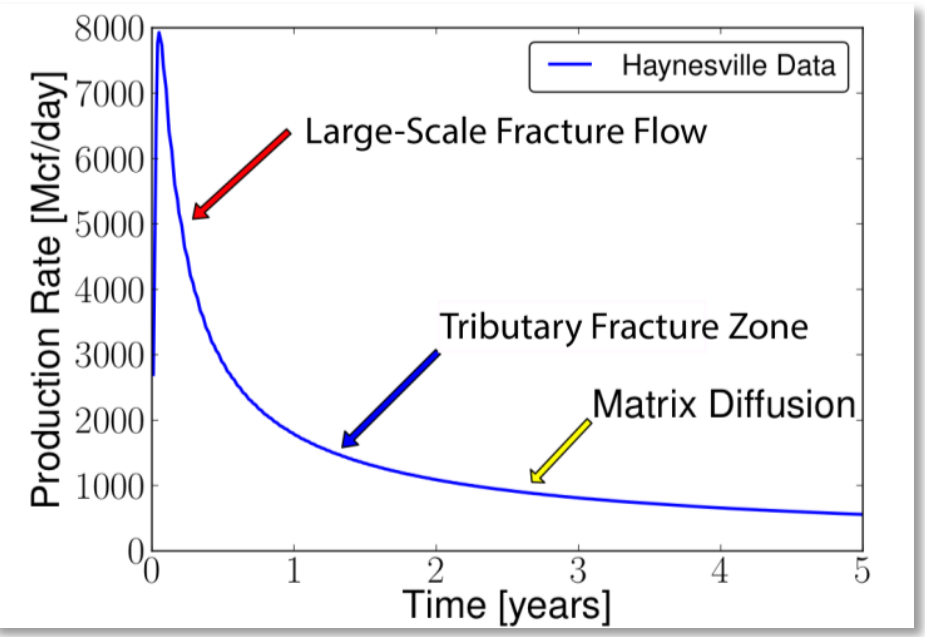

After the initial flush, transport at small scales dominates the production from fractured shales.

\section{Case Study Using Data from the MSEEL-I Site}

\begin{tabular}{|l|l|l|l|l|}
\hline Year & $\mathbf{1}$ & $\mathbf{2}$ & $\mathbf{5}$ & $\mathbf{1 0}$ \\
\hline $\begin{array}{l}\text { \% Fracture } \\
\text { Production }\end{array}$ & 99 & 95 & 75 & 40 \\
\hline $\begin{array}{l}\text { \% Matrix } \\
\text { Production }\end{array}$ & 1 & 5 & 25 & 60 \\
\hline
\end{tabular}

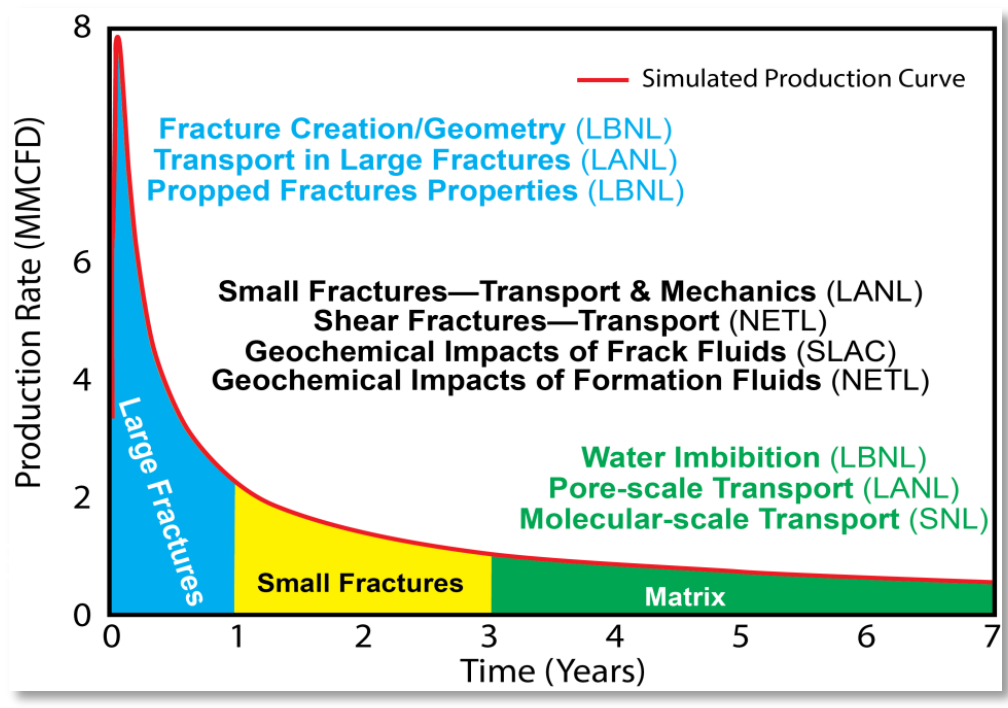

DOE is using its national labs to build the fundamental science on production from shales.

This foundation is being used to develop a new tools for simulating the production of fractured shales based on the physics of transport from pore-scale to reservoir-scale.

Applying these tools is leading to new strategies for increasing ultimate recovery (e.g., pressure management). 


\section{DOE's research has led to new, fast \& accurate platforms for predicting gas production from fractured shales.}
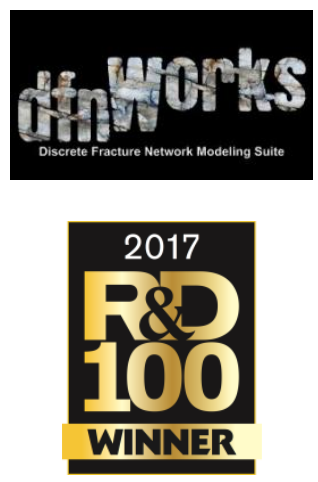
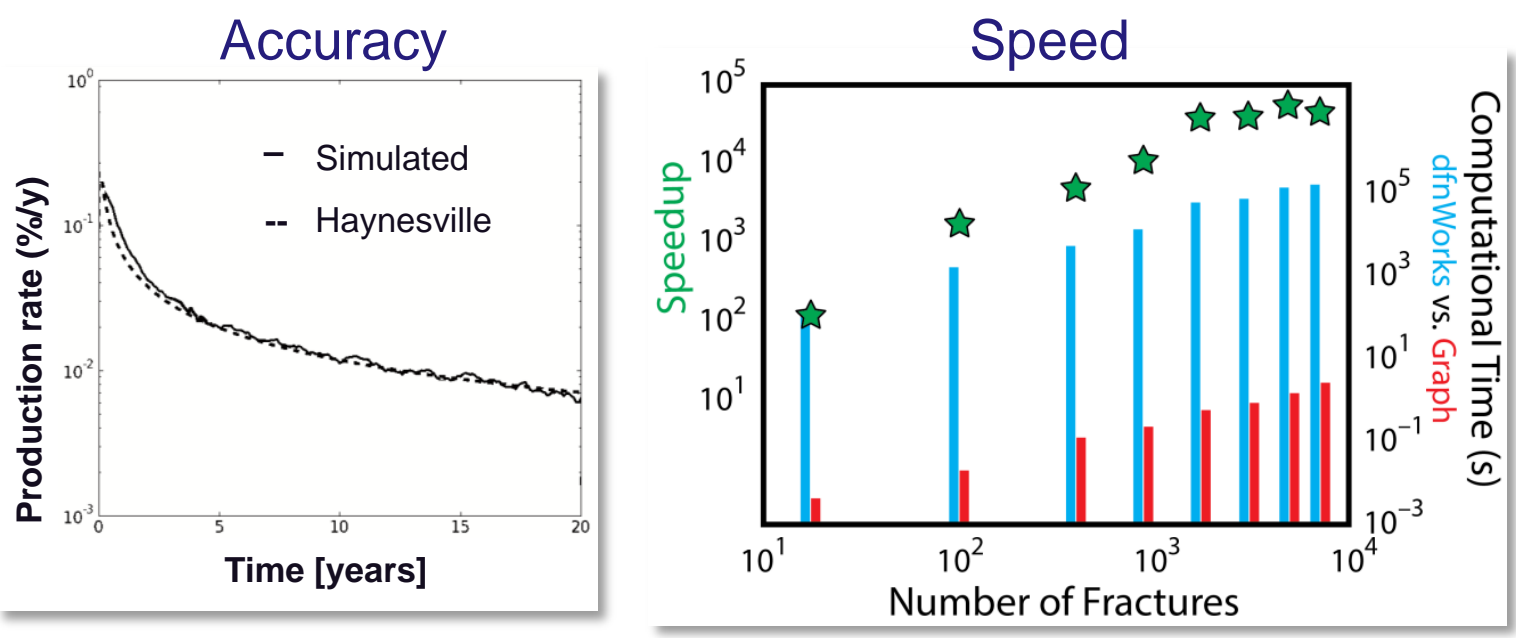

By combining graph-based models with full-physics discrete-fracture models, hydrocarbon production can be predicted accurately with orders of magnitude increases in speed. Full physics model includes matrixtransport and fracture-transport processes. LANL's dfnWorks is an open source software package.



DOE's Technology Commercialization Fund is helping to couple dfnWorks and graph-based models to Golder's FracMan platform 
Using data from the MSEEL-I site to calibrate our physics-based model, we have early results on pressure management.

\section{Next year, DOE hopes to provide quantitative insights for basins/plays.}

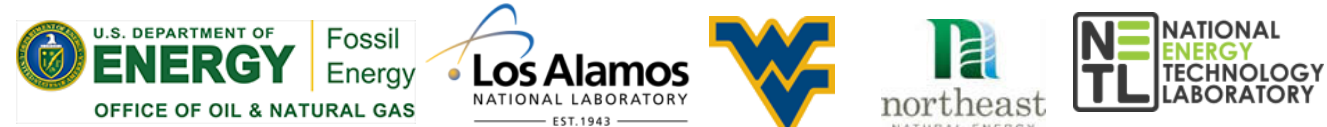

We have demonstrated the physical basis for pressure management using data from DOE's MSEEL-I field laboratory. Next year, we anticipate quantitative insights for both MSEEL \& other basins/plays.


For MSEEL-I, there appears to be an optimum drawdown rate that could increase recovery significantly over a rapid drawdown. 


\section{We have shown that both mechanical and chemical processes in the matrix can negatively impact production.}



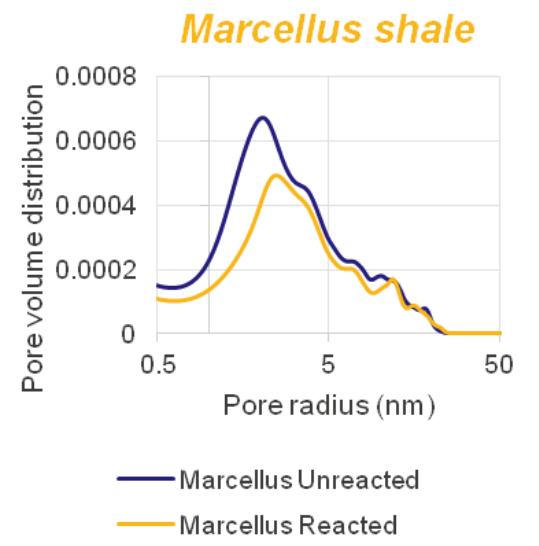

Porosity decreased by $13.48 \%$



Identified damage in matrix at can occur at high $\triangle \mathrm{P}$;

impacts both $C$ and $D$ depending on reservoir history

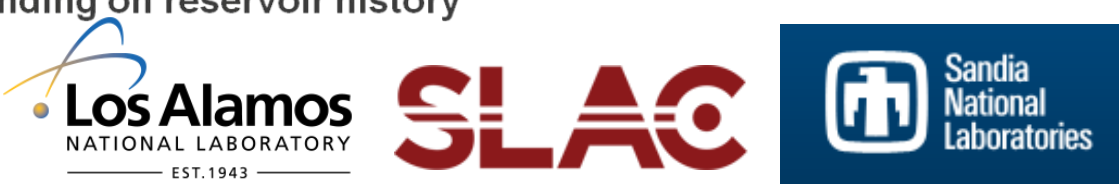

Based on our current work, we can only provide qualitative insights to operators today. An additional year of work would lead to quantitative guidelines on critical drawdown rates and chemical reactions that could damage reservoirs in different basins/plays. 